\title{
Using the Interval Type-2 Fuzzy Inference Systems to Compare the Impact of Speed and Space Perception on the Occurrence of Road Traffic Accidents
}

\author{
Marjana Čubranić-Dobrodolac ${ }^{1,2}$, Libor Švadlenka ${ }^{1} \oplus$, Svetlana Čičević ${ }^{2}$, \\ Aleksandar Trifunović ${ }^{2}$ and Momčilo Dobrodolac ${ }^{2, *(D)}$ \\ 1 Faculty of Transport Engineering, University of Pardubice, Studentská 95, 53210 Pardubice, Czech Republic; \\ marjana@sf.bg.ac.rs (M.Č.-D.); libor.svadlenka@upce.cz (L.Š.) \\ 2 Faculty of Transport and Traffic Engineering, University of Belgrade, Vojvode Stepe 305, \\ 11000 Belgrade, Serbia; s.cicevic@sf.bg.ac.rs (S.Č.); a.trifunovic@sf.bg.ac.rs (A.T.) \\ * Correspondence: m.dobrodolac@sf.bg.ac.rs; Tel.: +381-113091213
}

Received: 30 July 2020; Accepted: 3 September 2020; Published: 10 September 2020

\begin{abstract}
A constantly increasing number of deaths on roads forces analysts to search for models that predict the driver's propensity for road traffic accidents (RTAs). This paper aims to examine a relationship between the speed and space assessment capabilities of drivers in terms of their association with the occurrence of RTAs. The method used for this purpose is based on the implementation of the interval Type-2 Fuzzy Inference System (T2FIS). The inputs to the first T2FIS relate to the speed assessment capabilities of drivers. These capabilities were measured in the experiment with 178 young drivers, with test speeds of 30,50, and $70 \mathrm{~km} / \mathrm{h}$. The participants assessed the aforementioned speed values from four different observation positions in the driving simulator. On the other hand, the inputs of the second T2FIS are space assessment capabilities. The same group of drivers took two types of space assessment tests-2D and 3D. The third considered T2FIS sublimates of all previously mentioned inputs in one model. The output in all three T2FIS structures is the number of RTAs experienced by a driver. By testing three proposed T2FISs on the empirical data, the result of the research indicates that the space assessment characteristics better explain participation in RTAs compared to the speed assessment capabilities. The results obtained are further confirmed by implementing a multiple regression analysis.
\end{abstract}

Keywords: type-2 fuzzy inference systems; traffic simulator; traffic accidents; road safety; space perception; speed perception

\section{Introduction}

One of the biggest problems globally nowadays is the rate of road traffic accidents (RTAs) and deaths on roads. Each year, around 1.24 million people are killed in RTAs and up to 20-50 million injured [1,2]. The issue of road safety represents a social and economic concern, resulting in physical and mental injuries and immense loss of property [3]. The costs of the consequences of RTAs vary from $1 \%$ to $2 \%$ gross national product in underdeveloped and developing countries [2,4]. The current trends indicate that if urgent action is not taken, RTAs could be the seventh leading cause of death by the year 2030. Moreover, $90 \%$ of these deaths occur in underdeveloped and developing countries $[2,3,5]$.

Technology development makes vehicles more affordable, which results in a rapid increase in vehicle ownership. On the one hand, this results in an elevated likelihood of the occurrence of RTAs; however, on the other hand, this produces much more RTA data, offering more possibilities to obtain new knowledge in the traffic safety field. With the continuous development of research methods, 
computer performance, information processing, etc., many universities, research institutes, and safety agencies analyze RTA data in order to propose adequate safety measures [6,7].

The wealth of RTA data inevitably generates more explanatory variables that may provide more accurate models of explaining RTA occurrence. However, it is known that "more is not always better", especially for the prediction of RTAs, considering that a large number of variables may cause model overfitting [8,9]. In addition, this can impact accompanying activities such as long execution time and unreliable prediction results $[8,10]$.

The development of computers and software leads to the development of new types of vehicles. In the current market of new vehicles, safer driving can be recognized through vehicle tracking and smartphone applications that detect risky driving patterns such as speeding or inappropriate lane changing [11]. Furthermore, the appearance of partly or fully autonomous vehicles can significantly contribute to road safety, reducing the frequency of RTAs [11]. However, this is still far from everyday reality, even for the most progressive markets [11,12].

There are many random factors in the occurrence of RTAs; however, they are most often grouped considering the road, vehicle, and driver characteristics, such as vehicle speed, aggressive behavior, skills, etc. If a driver has developed spatial skills while in traffic, his or her attention will be focused on the traffic situation, otherwise, it will be distracted and directed to orientation in space $[13,14]$. On the other hand, some reports indicate that speeding is a contributing factor in about one-third of all fatal RTAs [15].

Considering all of the above, a motive to carry out the research described in this paper is to offer a model whose implementation would contribute to the explanation of causes of RTAs. The experimental research was conducted to examine the impact of vehicle speed and space assessment capabilities on the occurrence of RTAs.

Speed does not only affect the severity of a crash but is also related to the risk of being involved in an RTA [16]. The dominant forms of improper driving during the late twentieth century were speeding, driving too fast for the existing conditions, improper lane changing, and improper passing $[17,18]$. Many empirical studies generally confirmed a positive relationship between traffic speed and the frequency of RTAs [19-22]. At the same time, some studies found that higher speeds do not necessarily result in higher accident rates $[23,24]$. It is suggested that the speed-RTA relationship should be considered in the proper context, accounting for possible additional confounding factors such as traffic exposure and road conditions [24-26], however including a perception of vehicle speed. Speeding, but also an inaccurate vehicle speed, is associated with an increased risk of being involved in a crash.

The current state in the considered field in the Republic of Serbia, the country where our research was carried out, is illustrated by the survey conducted by the state authorities in the period from 2017 to 2019. This survey shows that about half of drivers in urban areas exceed the speed limit (2017-49.4\%; $2018-48.4 \% ; 2019-51 \%$ ) [27]. When it comes to the circumstances and causes of RTAs, the results for this period indicate that the largest number of the worst RTAs, as well as the largest number of fatalities, belong to the category of unadjusted speed $(2017-53.14 \% ; 2018-52.14 \% ; 2019-51.41 \%$ of the cases where the cause of RTAs with fatalities is unadjusted speed) [28]. According to the Road Traffic Safety Agency in Serbia [27], based on the responses of the participants, every third driver of a passenger car exceeds the speed limit in urban areas by an average of more than $10 \mathrm{~km} / \mathrm{h}$. When it comes to the speed of vehicles outside urban areas, the results show that almost two-fifths of the participants drive at a speed that is higher than the limit. A survey of drivers' attitudes to speeding in the Republic of Serbia pointed to the alarming fact that the largest percentage of drivers (41.7) do not agree that speeding in populated areas by $10 \mathrm{~km} / \mathrm{h}$ increases the risk of being involved in an RTA. The decision on the level of vehicle speed is influenced by the driver's psychological traits, driving skills and limitations, road and environment characteristics, and vehicle characteristics, but also by the space assessment capabilities of the driver.

Driving skills involve processes such as the perception of time, speed, and especially space. How important these skills are for safe participation in traffic is widely explained in the literature. 
A well-known term introduced for describing someone's position in traffic related to their skills is situation awareness. This term can be defined as $[29,30]$ "the perception of the elements in the environment within a volume of time and space, the comprehension of their meaning, and the projection of their status in the near future". The aforementioned abilities are connected to the largest number of RTAs that are caused by the human factor. There are findings that the human factor is responsible for $93 \%$ of all RTAs [31,32]. From all the above, it can be noticed how important is to examine the perception of speed and space of drivers. A motive to carry out the research described in this paper is to offer a model whose implementation would contribute to the explanation of the causes of RTAs. The experimental research was conducted to examine the impact of vehicle speed and space assessment capabilities on the occurrence of RTAs.

Because the answers of participants related to the assessment of speed and space involve a certain level of imprecision and fuzziness, we assumed that the implementation of fuzzy inference systems would be a convenient tool for data processing. Fuzzy logic is widely used for explaining driver behavior. The previous implementation can be segmented as follows [33]: examination of the interaction between the driver and road infrastructure [34]:, examination of the interaction between the driver and in-vehicle systems [35], testing the psychophysical characteristics of drivers [33,36,37], and determining a driving style $[38,39]$. The motivation to use fuzzy logic for modeling the propensity for RTAs based on speed assessments and spatial abilities of drivers is actually the introduction of a new field of implementation. This new area can be called the perception of road traffic conditions and relations.

In this paper we propose the implementation of the interval Type-2 Fuzzy Inference System (T2FIS). Three T2FIS structures are designed and tested on the empirical data collected in two experiments. The T2FIS that gives the lowest error in the description of data can be considered as the most convenient in explaining the relationship between the inputs-characteristics of the driver, and output-the number of RTAs. The proposed T2FIS can be used as a decision-making tool to calculate the propensity for participation in accidents.

\section{Methods}

This section is divided into two subsections. The first refers to the description of experiments carried out with the aim of empirical data collection. The second subsection is about the design of T2FIS structures.

\subsection{Data Collection}

The empirical data are collected in the experiment which consists of two testing sessions, which will be designated as Experiment I and Experiment II in the further text. The task of the respondents in Experiment I was to estimate the passenger car speed. Experiment II was designed to explore the respondent's spatial abilities. Along with the tests related to the assessment of speed and spatial capabilities, the participants also filled the demographic questionnaire and the questionnaire about participation in RTAs. The main purpose of these additional questionnaires was to provide information about the number of RTAs experienced by participants, which were then used as an output variable in the implemented models.

\subsubsection{Participants}

The experiments were conducted in the Laboratory of Traffic Psychology, Faculty of Transport and Traffic Engineering, in Belgrade. The participants in the experiment were recruited from 178 young drivers (96 males and 82 females). Our participants' mean age was 22.05 years (standard deviation (SD) $=2.12$ ). The experimental procedure (instructions, the method of testing, and data collection) were the same for all participants who took part in both experiments and also completed questionnaires on demographic data and involvement in RTAs. The research adhered to the Code of Ethics and Conduct of the Serbian Psychological Association. The participants also signed a written voluntary informed 
consent which confirms their willingness to take part in this research. The participants did not receive any compensation for taking part in the survey as well.

\subsubsection{Experiment I}

For the purpose of this experiment, three different speed levels of a moving vehicle were presented to the participants in the driving simulator. Both experiments were carried out in a PC-based driving simulator, which incorporates three 4200 plasma monitors that provide the respondents a $180^{\circ}$ horizontal and $50^{\circ}$ vertical field of view of the simulated environment $[40,41]$.

The vehicle used for the experiment was a Peugeot 307. The color of the vehicle was bright yellow. In the literature, it is possible to discover the findings on the relationship between vehicle color and its perception on the road. There is evidence that it is easier to spot the vehicle having a higher contrast between the vehicle color and the environment. More concrete, brighter colored cars provide a lot of contrast between the vehicles and their surroundings; therefore, it is easier to notice them [41-43].

In Experiment I, the vehicle was observed from four positions. These were the following: the first was a front view of the vehicle, which meant that the vehicle was approaching, the second was a back view, which implied that the vehicle was moving away, the third was a side view, indicating that the vehicle was passing by, and the fourth was a view from inside the vehicle, which represented the situation when a driver was behind the wheel, but without information about vehicle speed from the instruments (Figure 1). Every participant estimated all of the three vehicle speed levels, from each viewing position.

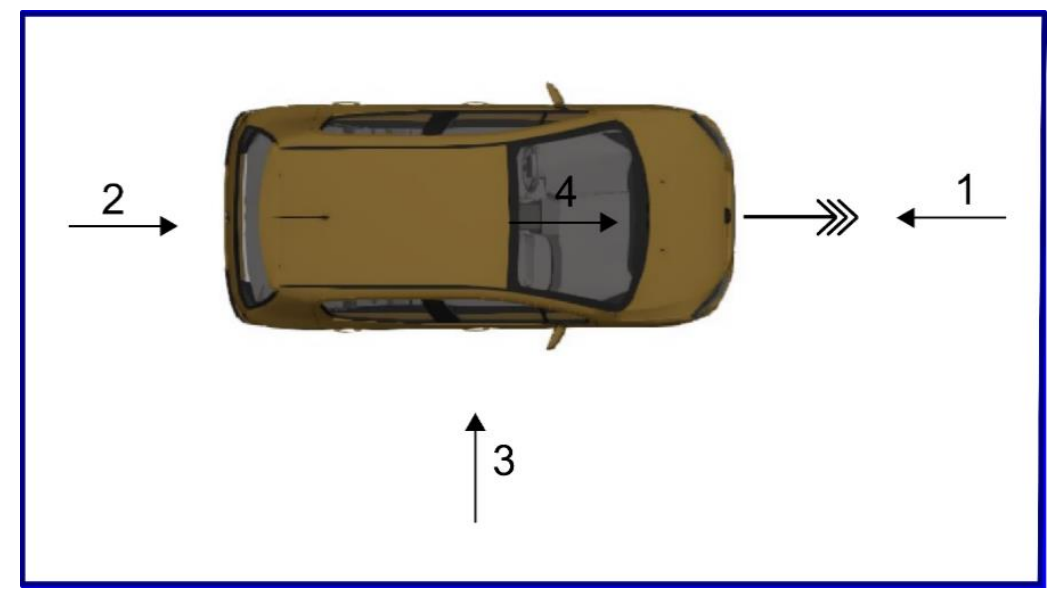

Figure 1. Observation positions in Experiment I: 1-Front view; 2-Back view; 3-Side view; 4-Driver's seat perspective.

In total, each participant made 12 assessments of speed. In the calculation process, to form three input variables based on speed assessment capabilities, the errors in the assessment are grouped around each of three speed levels. This implies a calculation of average assessment error from four positions, per particular speed level. The units for both, speed levels and the errors in the assessments are the same- $\mathrm{km} / \mathrm{h}$.

The three test speed levels were $30 \mathrm{~km} / \mathrm{h}, 50 \mathrm{~km} / \mathrm{h}$, and $70 \mathrm{~km} / \mathrm{h}$. They were chosen due to the most often legal limitations: the limit of $30 \mathrm{~km} / \mathrm{h}$ is usually set in a school zone; limit of $50 \mathrm{~km} / \mathrm{h}$ in the inhabited area; and the limit of $70 \mathrm{~km} / \mathrm{h}$ outside of the inhabited area $[41,44,45]$. The respondents were asked to report the perceived vehicle speed for each experimental condition. The experimenter entered the declared value into the adequate space in the on-line questionnaire previously prepared for the purpose of this study. The questionnaire also covered demographic variables, as well as those related to participation and the number of experienced RTAs [41,45].

Specific speed/position combination was randomly assigned to each participant, i.e., the stimulus order was determined using a random number generator. This was done in order to avoid the 
anchoring effect, employing counterbalancing. Counterbalancing was achieved by randomizing the series of presentations of the test stimuli [41].

\subsubsection{Experiment II}

For Experiment II, 2D and 3D spatial tests were used. The objects were positioned with random orientation in space. All participants had the same viewing position on all tasks. The background was dark, to standardize the local contrasts [46,47]. Examples of 2D and 3D tests are shown in Figure 2.

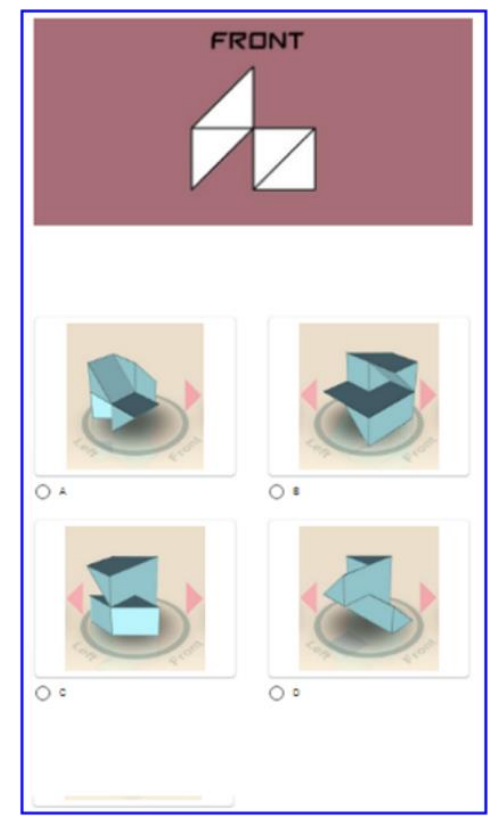

(a)

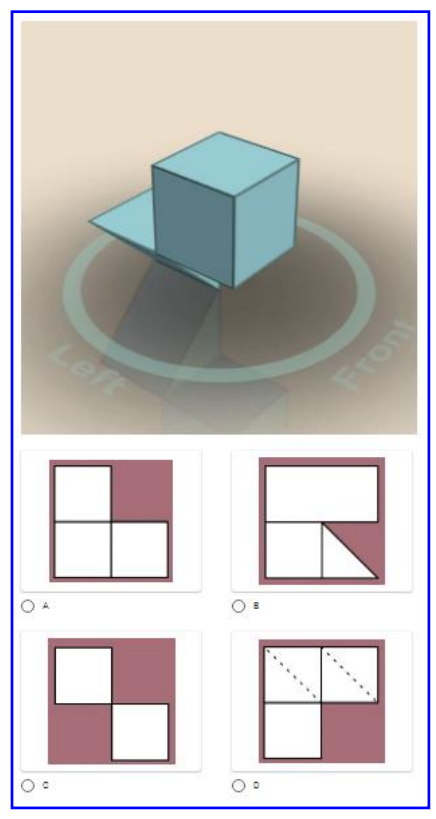

(b)

Figure 2. The appearance of the task used in experiment II: (a) an example of a 2D test used in the experiment; (b) an example of a 3D test used in the experiment.

In the laboratory with reduced environmental light, all participants were placed in the same position with a $58 \mathrm{~cm}$ distance between their head and the center of the screen. The tests were displayed on the same monitor that was used in the driving simulator. 2D and 3D tests presentation order was randomized. As in the case of Experiment I, in the beginning, each participant was assigned the specific combination of an experimental test order, which was regulated by using a random number generator. In the 2D test, respondents are asked to find for the given object shown in 2D the appropriate object in 3D (example in Figure 2a). Similarly, when it comes to the 3D task, the respondent had to find an object in 2D for the assigned object shown in 3D (example in Figure 2b).

\subsection{Model Development}

The models proposed in this paper are based on testing of the Mamdani based T2FIS [48]. The principles of Type-2 fuzzy sets were first proposed and described by Zadeh [49] to expand the possibilities and performance of the standard Type- 1 fuzzy sets. The main characteristic of Type- 2 fuzzy sets is that they integrate uncertainty about the membership function (MF). For this reason, MF is defined by the corresponding interval bounded by two functions, a lower MF and upper MF, and called the Footprint of Uncertainty (FOU), as illustrated in Figure 3. 


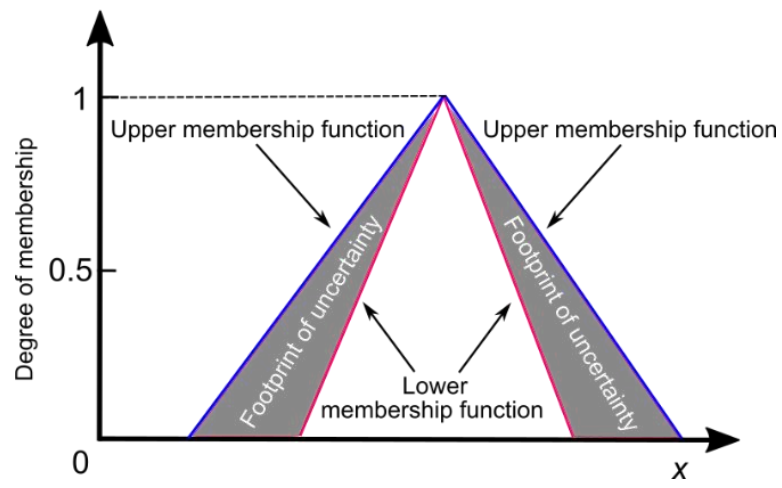

Figure 3. The footprint of uncertainty for an interval Type-2 fuzzy set.

The performance of three T2FIS structures was compared. In the first, there were input variables related to speed assessment capabilities (Figure 4a), in the second, the space assessment capabilities were inputs to the model (Figure $4 \mathrm{~b}$ ), and in the third, the speed and space assessments were jointly considered as inputs (Figure 4c). All three structures had the same output variable-the number of experienced RTAs.

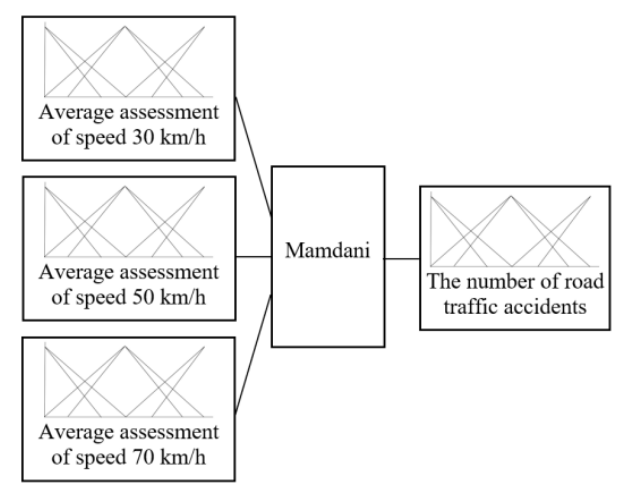

(a)

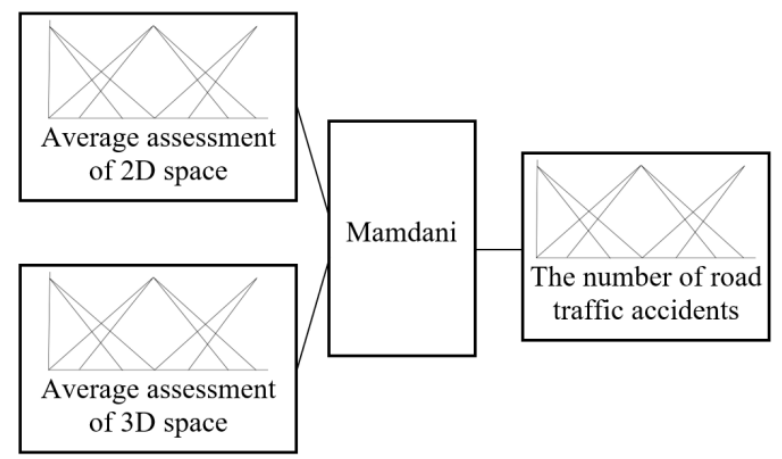

(b)

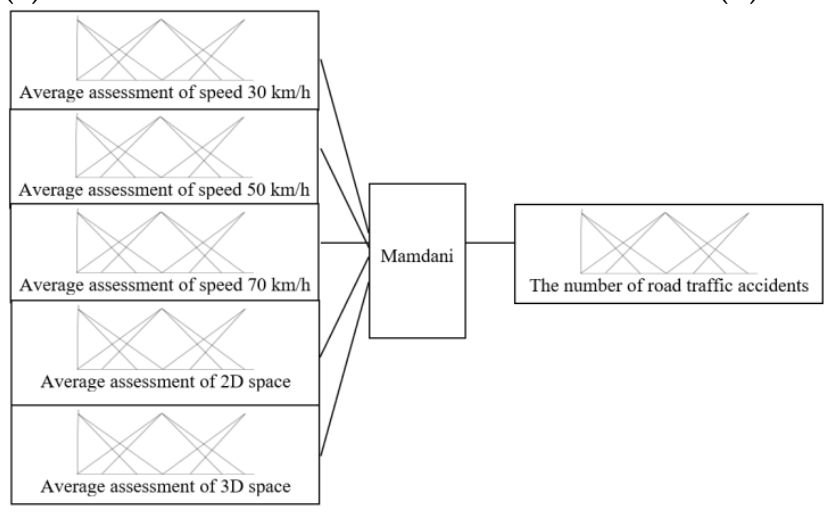

(c)

Figure 4. Configuration of the research: (a) the model of speed assessment capabilities-T2FIS_speed; (b) the model of space assessment capabilities-T2FIS_space; (c) the model that encompasses all considered input variables_T2FIS_speed_and_space.

In the figures, as well as in the tables, we use the following notation: T2FIS related to the speed assessment capabilities is designated as T2FIS_speed, T2FIS related to the space assessment capabilities is labeled as T2FIS_space, and T2FIS that jointly considers both categories is marked as T2FIS_speed_and_space. 
The first fuzzy inference system has three input variables: Average assessment of speed $30 \mathrm{~km} / \mathrm{h}$, Average assessment of speed $50 \mathrm{~km} / \mathrm{h}$, and Average assessment of speed $70 \mathrm{~km} / \mathrm{h}$. In all three cases, the word "average" is used because the assessments were performed from four positions-front, rear, side view, and from the position of a driver. Therefore, each of the three input variables is the arithmetic mean of four measurements.

Input variables that relate to the speed assessment take the values of average errors that are made when estimating the real speed of the car. The minimum, mean, maximum values, and standard deviation of each variable of the examined sample of 178 young drivers are given in Table 1 . It can be noted that in some cases very huge errors in the assessments are recorded. The young age of participants and their humble driving experience may be an explanation for such results.

Table 1. Description of a sample considering errors in speed assessment.

\begin{tabular}{ccccc}
\hline \multirow{2}{*}{ Input Variable } & \multicolumn{3}{c}{ Average Errors in Assessments from Four Different Positions [km/h] } \\
\cline { 2 - 4 } & Minimum & Mean & Maximum & Standard Deviation \\
\hline Average assessment of speed $30 \mathrm{~km} / \mathrm{h}$ & -3.75 & 21.75 & 67.50 & 11.68 \\
Average assessment of speed $50 \mathrm{~km} / \mathrm{h}$ & -18.75 & 13.57 & 62.50 & 13.51 \\
Average assessment of speed $70 \mathrm{~km} / \mathrm{h}$ & -54.50 & -32.33 & 15.00 & 10.06 \\
\hline
\end{tabular}

Input variable Average assessment of speed $30 \mathrm{~km} / \mathrm{h}$ is displayed using five fuzzy sets and their membership functions (Figure 5): U_30-Average assessment is under $30 \mathrm{~km} / \mathrm{h}$, A_30-Average assessment is around $30 \mathrm{~km} / \mathrm{h}$, MO_30-Average assessment is moderately over $30 \mathrm{~km} / \mathrm{h}$, SO_30—Average assessment is significantly over $30 \mathrm{~km} / \mathrm{h}$ and EO_30_Average assessment is much higher than $30 \mathrm{~km} / \mathrm{h}$. This variable is marked as $x_{1}$.

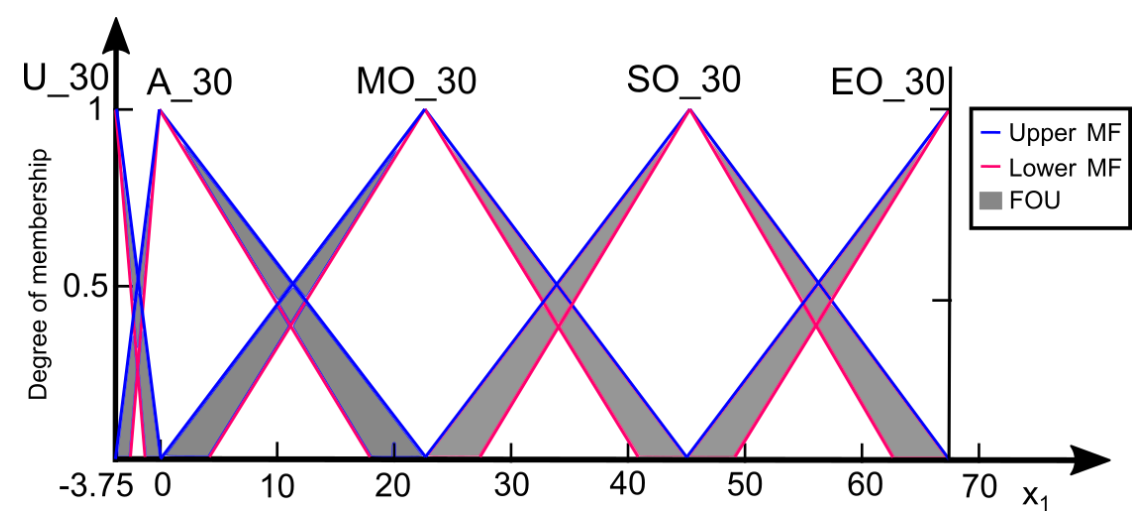

Figure 5. Input variable Average assessment of speed $30 \mathrm{~km} / \mathrm{h}$. Used notation: MF-membership function; FOU-footprint of uncertainty.

Input variable Average assessment of speed $50 \mathrm{~km} / \mathrm{h}$ is displayed using five fuzzy sets and their membership functions (Figure 6): U_50-Average assessment is under $50 \mathrm{~km} / \mathrm{h}$, A_50—Average assessment is around $50 \mathrm{~km} / \mathrm{h}$, MO_50_Average assessment is moderately over $50 \mathrm{~km} / \mathrm{h}$, SO_50—Average assessment is significantly over $50 \mathrm{~km} / \mathrm{h}$ and EO_50-Average assessment is extremely over $50 \mathrm{~km} / \mathrm{h}$. This variable is marked as $x_{2}$.

Input variable Average assessment of speed $70 \mathrm{~km} / \mathrm{h}$ is displayed using five fuzzy sets and their membership functions (Figure 7): EU_70-Average assessment is greatly under $70 \mathrm{~km} / \mathrm{h}$, SU_70Average assessment is significantly under $70 \mathrm{~km} / \mathrm{h}, \mathrm{MU} \_70$ - Average assessment is moderately under $70 \mathrm{~km} / \mathrm{h}$, A_70_Average assessment is around $70 \mathrm{~km} / \mathrm{h}$, and O_70—Average assessment is over $70 \mathrm{~km} / \mathrm{h}$. This variable is marked as $x_{3}$. 


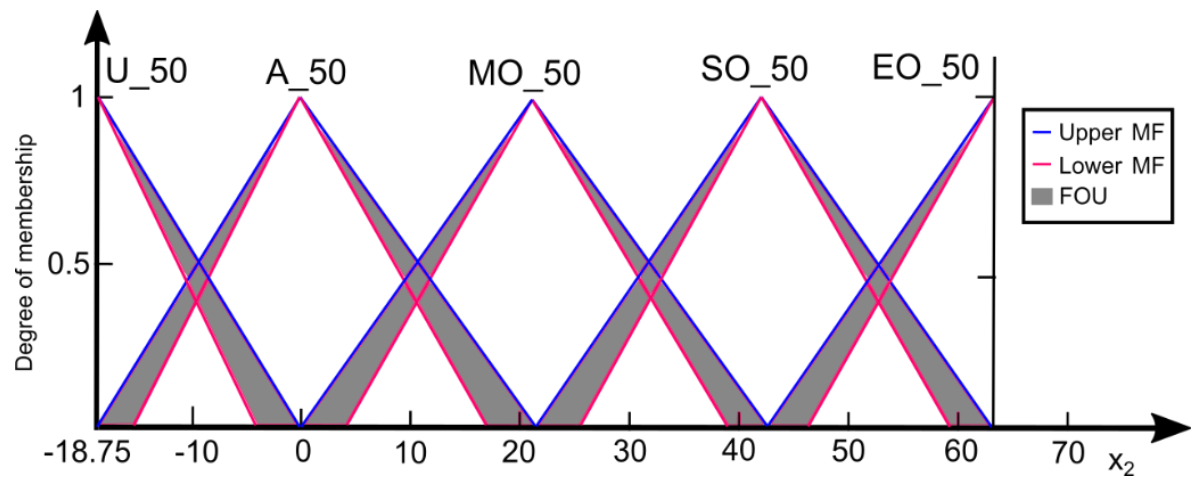

Figure 6. Input variable Average assessment of speed $50 \mathrm{~km} / \mathrm{h}$. Used notation: MF-membership function; FOU-footprint of uncertainty.

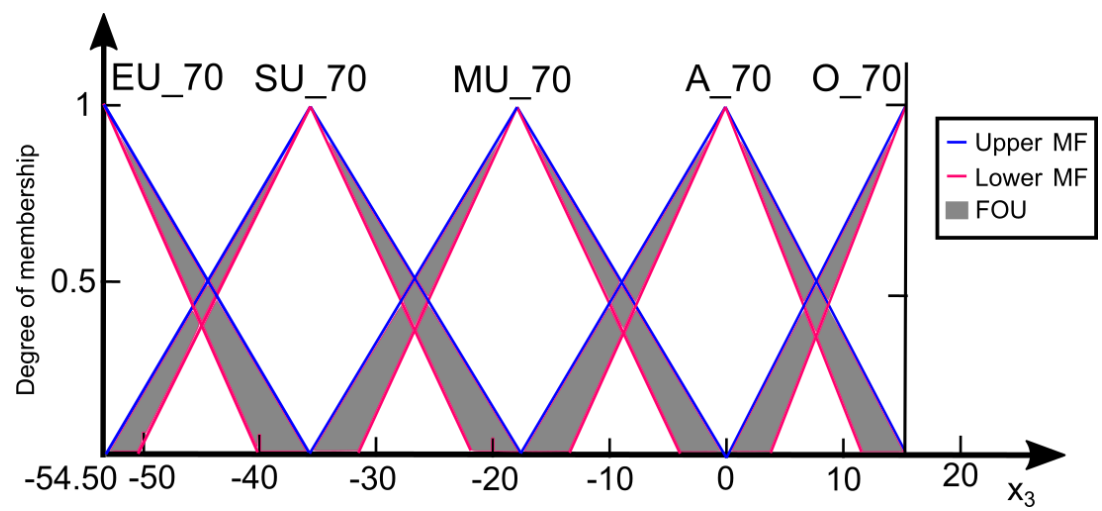

Figure 7. Input variable Average assessment of speed $70 \mathrm{~km} / \mathrm{h}$. Used notation: MF-membership function; FOU-footprint of uncertainty.

The output variable named The number of experienced road traffic accidents is the same, as previously explained, in both fuzzy inference systems. Since the sample consists of young drivers, the number of reported RTAs is relatively small-the minimum value is 0 and the maximum is 3 . Accordingly, the output variable is defined by three fuzzy sets (Figure 8): SNA-a small number of road traffic accidents, MNA - a moderate number of road traffic accidents, and HNA - high number of road traffic accidents. This variable is marked as $y$.

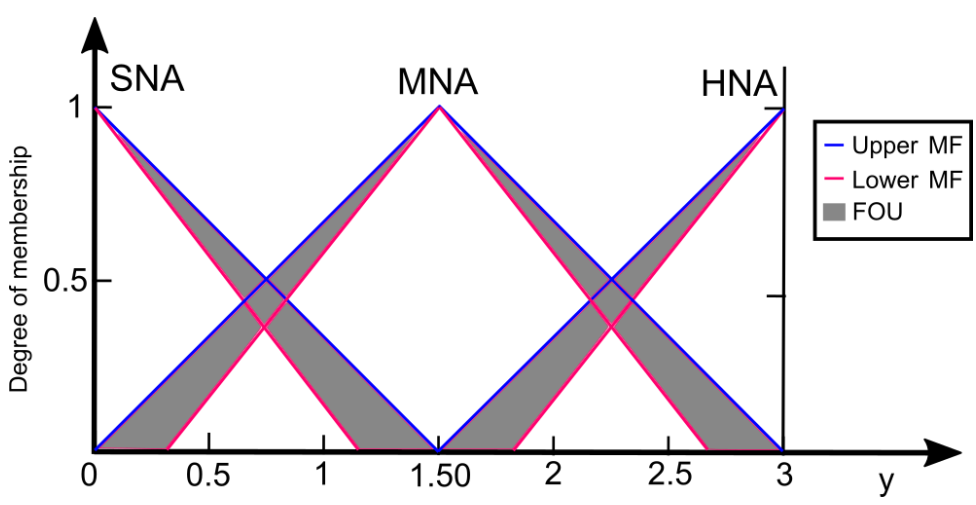

Figure 8. Output variable the number of experienced road traffic accidents. Used notation: MFmembership function; FOU-footprint of uncertainty.

On the other hand, the second fuzzy inference system is based on two input variables that describe the space assessment capabilities. Unlike in the case of speed assessment, where the errors were considered, in this case, each examinee is rated by the grade from 0 to 5 depending on the success on 
the 2D and 3D spatial abilities test. The minimum, mean, maximum values, and standard deviation of considered variables in the examined sample of 178 young drivers are shown in Table 2.

Table 2. Description of a sample considering errors in space assessments.

\begin{tabular}{ccccc}
\hline \multirow{2}{*}{ Input Variable } & \multicolumn{3}{c}{ Average Marks from the Space Assessments Tests } \\
\cline { 2 - 5 } & Minimum & Mean & Maximum & Standard Deviation \\
\hline Average assessment of 2D space & 0 & 1.81 & 5 & 1.12 \\
Average assessment of 3D space & 0 & 1.67 & 5 & 1.01 \\
\hline
\end{tabular}

Input variable Average assessment of $2 D$ space is described using five fuzzy sets and their membership functions (Figure 9): VSM_2-Very small mark, SM_2-Small mark, MM_2-Middle mark, HM_2-High mark, and VHM_2-Very high mark. This variable is marked as $x_{4}$.

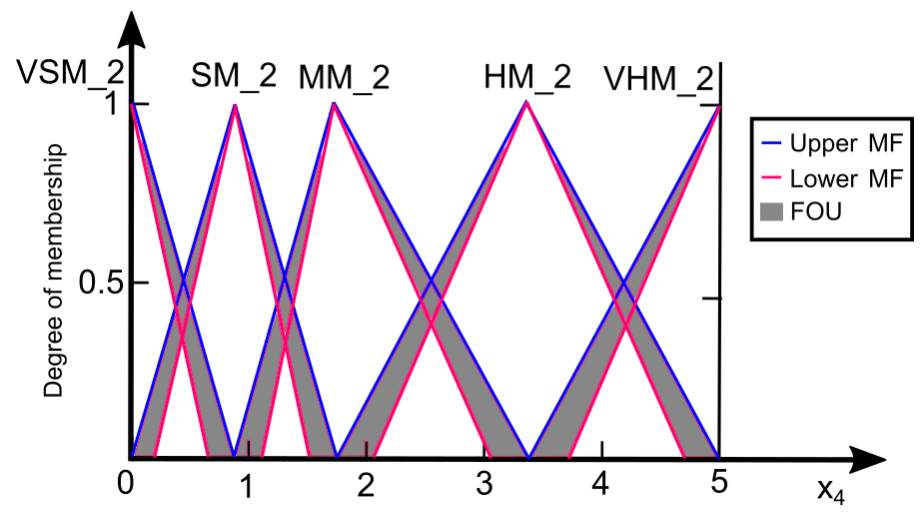

Figure 9. Input variable Average assessment of 2D space. Used notation: MF-membership function; FOU-footprint of uncertainty.

Input variable Average assessment of $3 D$ space is described using five fuzzy sets and their membership functions (Figure 10): VSM_3-Very small mark, SM_3-Small mark, MM_3-Middle mark, HM_3-High mark, and VHM_3-Very high mark. This variable is marked as $x_{5}$.

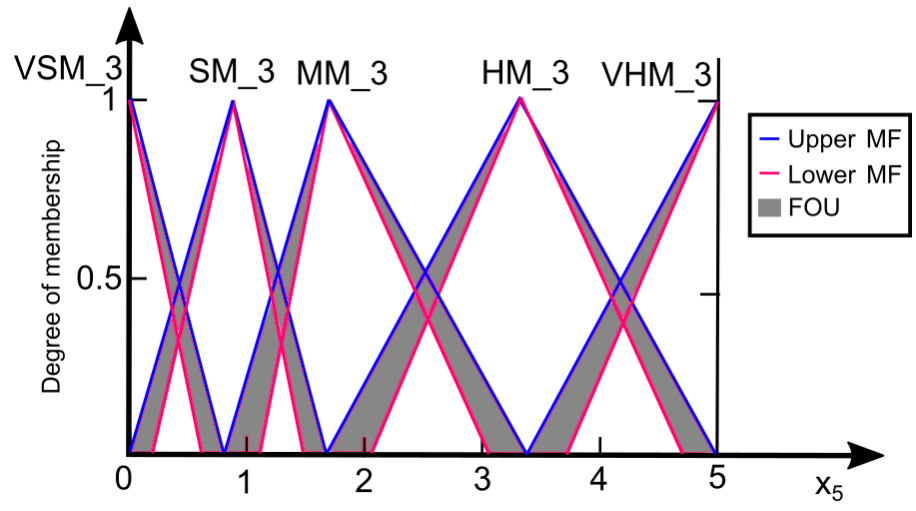

Figure 10. Input variable Average assessment of 3D space. Used notation: MF-membership function; FOU-footprint of uncertainty.

The fuzzy rule base is crucial for the performance of a T2FIS. Here, we use a well-known principle for defining fuzzy rules based on the empirical data introduced by Wang and Mendel (WM) [50].

This approach implies generating one fuzzy rule per one data pair, i.e., per one participant. In our case, there are 178 participants in the sample, and accordingly, 178 fuzzy rules should be formed. However, certain rules are the same or conflicting. The conflicting rules have the same "IF" part, but a 
different "THEN" part. First, from the same rules, just one should be left. Furthermore, we need to eliminate the conflicting rules. To decide which rules will be retained in the final fuzzy rules database, the procedure involves the calculation of the degree of significance for each of the formed rules. This is done by Equation (1), for the rule defined in the following way: "IF $x_{1}$ is $\mathrm{A}$ and $x_{2}$ is B, THEN $y$ is C". In a group of conflicting rules, only the rule with the maximum degree should be retained. $D(R u l e)$ is the importance degree of a rule, $\mu_{A}\left(x_{1}\right)$ is a value of the membership function of the region A when the input value is $x_{1}$, etc.

$$
D(\text { Rule })=\mu_{A}\left(x_{1}\right) * \mu_{B}\left(x_{2}\right) * \mu_{C}(y)
$$

The implemented programming code for this purpose is based on the code presented in the paper by Čubranić-Dobrodolac et al. [33]. After the required calculations, there are 22 fuzzy rules obtained based on the empirical data, considering the sample of 178 participants, in the case of speed assessment capabilities (Table 3), while as regards spatial abilities assessment, there are 17 fuzzy rules obtained by the same approach (Table 4). Finally, in the T2FIS where all input variables are jointly considered, 84 fuzzy rules are generated from the empirical data based on the WM approach (Table A1 in Appendix A).

Table 3. The fuzzy rules obtained from empirical data in the case of speed capabilities assessment.

\begin{tabular}{ccccc}
\hline $\boldsymbol{D}($ Rule $)$ & $\begin{array}{c}\text { Serial No. of MF } \\
\text { for Variable } \boldsymbol{x}_{\mathbf{1}}\end{array}$ & $\begin{array}{c}\text { Serial No. of MF } \\
\text { for Variable } \boldsymbol{x}_{\mathbf{2}}\end{array}$ & $\begin{array}{c}\text { Serial No. of MF } \\
\text { for Variable } \boldsymbol{x}_{\mathbf{3}}\end{array}$ & $\begin{array}{c}\text { Serial No. of MF } \\
\text { for Variable } \boldsymbol{y}\end{array}$ \\
\hline 1 & 1 & 1 & 1 & 1 \\
0.42682 & 2 & 1 & 1 & 1 \\
0.25945 & 2 & 1 & 2 & 1 \\
0.54222 & 2 & 2 & 1 & 1 \\
0.62963 & 2 & 2 & 2 & 1 \\
0.29929 & 3 & 2 & 1 & 1 \\
0.68531 & 3 & 2 & 2 & 1 \\
0.47288 & 3 & 2 & 3 & 1 \\
0.35178 & 3 & 3 & 1 & 1 \\
0.85328 & 3 & 3 & 2 & 1 \\
0.74074 & 3 & 4 & 3 & 1 \\
0.33383 & 3 & 4 & 2 & 1 \\
0.27160 & 3 & 3 & 3 & 1 \\
0.24294 & 4 & 3 & 2 & 1 \\
0.30423 & 4 & 4 & 3 & 1 \\
0.48971 & 4 & 4 & 2 & 1 \\
0.67901 & 4 & 4 & 3 & 1 \\
0.50440 & 4 & 4 & 4 & 1 \\
0.37940 & 4 & 5 & 3 & 1 \\
0.65040 & 5 & 4 & 5 & 2 \\
0.10539 & 5 & 5 & 3 & 1 \\
0.72222 & 5 & 5 & 4 & \\
\hline
\end{tabular}

Table 4. The fuzzy rules obtained from the empirical data in the case of space capabilities assessment.

\begin{tabular}{cccc}
\hline $\boldsymbol{D}($ Rule $)$ & Serial No. of MF for Variable $\boldsymbol{x}_{\mathbf{4}}$ & Serial No. of MF for Variable $x_{\mathbf{5}}$ & Serial No. of MF for Variable $y$ \\
\hline 1 & 1 & 1 & 1 \\
0.79518 & 1 & 2 & 1 \\
0.79640 & 1 & 3 & 1 \\
0.80239 & 1 & 4 & 1 \\
0.88888 & 2 & 1 & 1 \\
0.70682 & 2 & 2 & 1 \\
0.70791 & 2 & 3 & 1 \\
0.71324 & 2 & 4 & 1 \\
\hline
\end{tabular}


Table 4. Cont.

\begin{tabular}{cccc}
\hline $\boldsymbol{D}($ Rule $)$ & Serial No. of MF for Variable $\boldsymbol{x}_{\mathbf{4}}$ & Serial No. of MF for Variable $\boldsymbol{x}_{\mathbf{5}}$ & Serial No. of MF for Variable $\boldsymbol{y}$ \\
\hline 0.87500 & 3 & 1 & 1 \\
0.69578 & 3 & 2 & 1 \\
0.69685 & 3 & 3 & 1 \\
0.70209 & 3 & 4 & 1 \\
0.75000 & 4 & 1 & 1 \\
0.59638 & 4 & 2 & 1 \\
0.59730 & 4 & 3 & 1 \\
0.60179 & 4 & 4 & 1 \\
1 & 5 & 5 & 1 \\
\hline
\end{tabular}

\section{Results and Discussion}

Finally, the defined T2FIS structures should be tested. This is accomplished based on Equation $(2)[51,52]$. Cumulative deviation $(C D)$ is a parameter that describes how good a T2FIS describes the empirical data. It represents a sum of absolute values of the difference between the number of RTAs experienced by the drivers from the sample and the corresponding results of T2FIS based on the input values for each driver from the sample. The result of the T2FIS for an examinee number $i$ in Equation (1) is marked as T2FIS(i).

$$
C D=\sum_{i=1}^{178}\left|y^{(i)}-T 2 F I S(i)\right|
$$

$C D$ is a cumulative deviation; $y^{(i)}$ represents the number of RTAs experienced by the driver from the sample; T2FIS(i) is the result of the interval Type-2 fuzzy inference system.

Following all the calculations, we are in a position to obtain the final result for the three considered fuzzy inference systems. In the first case, $C D$ value for the interval Type- 2 fuzzy inference system related to the speed assessment capabilities is equal to 97.6477. Further, CD value for the T2FIS related to the space assessment capabilities is equal to 91.7891. Finally, testing the T2FIS where all five considered independent variables are entered as inputs showed that CD value is 103.4103. A comparison of empirical data and results of T2FIS structures are graphically shown in Figures 11-13.

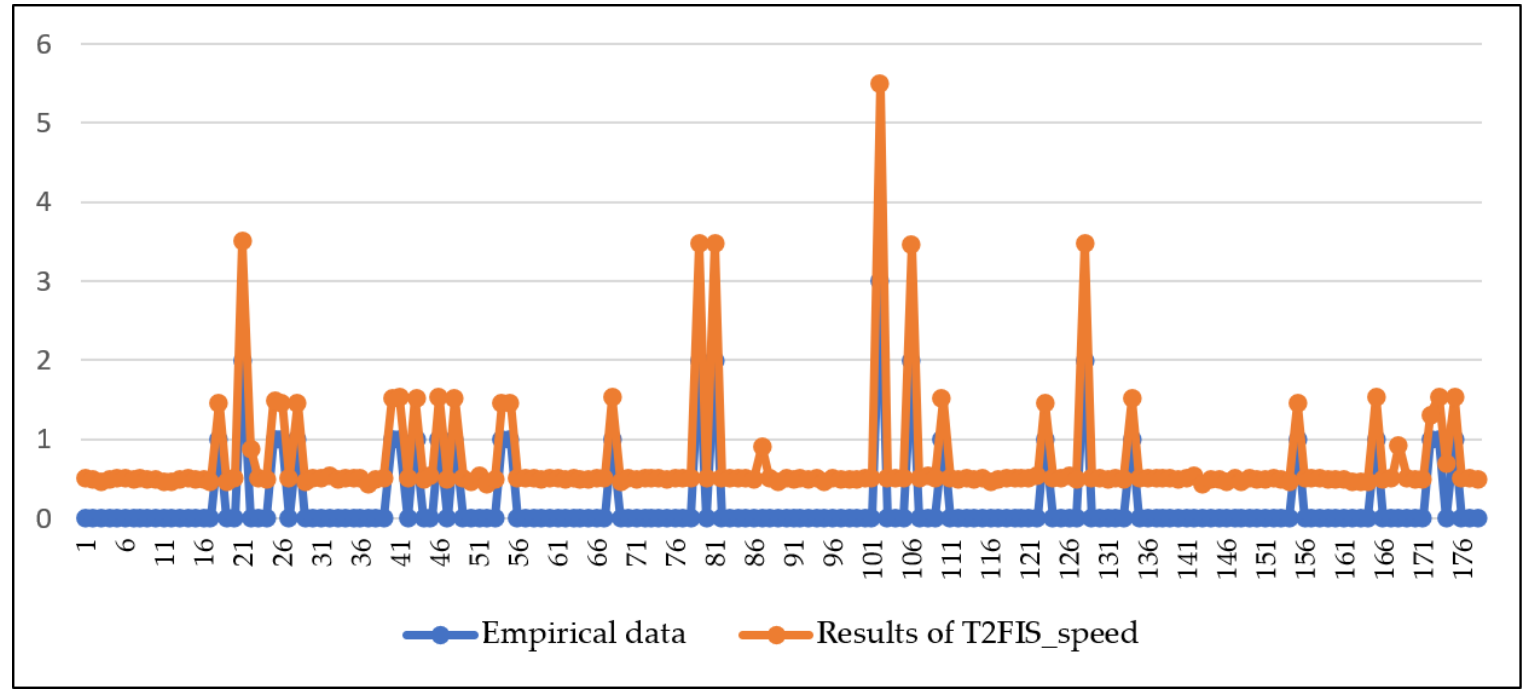

Figure 11. A comparison of empirical data and results of the Type-2 Fuzzy Inference System (T2FIS) in the case of speed capabilities assessment-T2FIS_speed. 


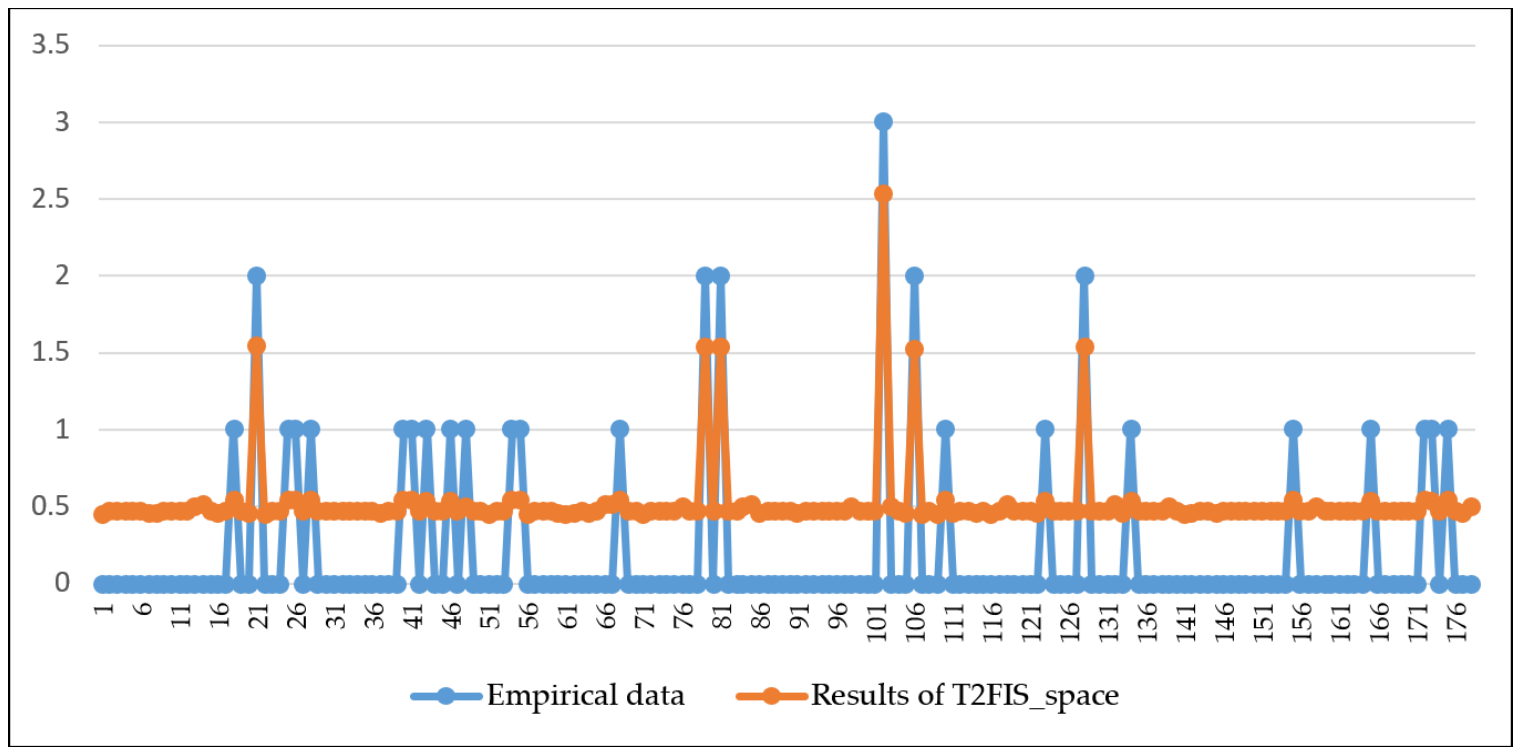

Figure 12. A comparison of empirical data and results of T2FIS in the case of space capabilities assessment-T2FIS_space.

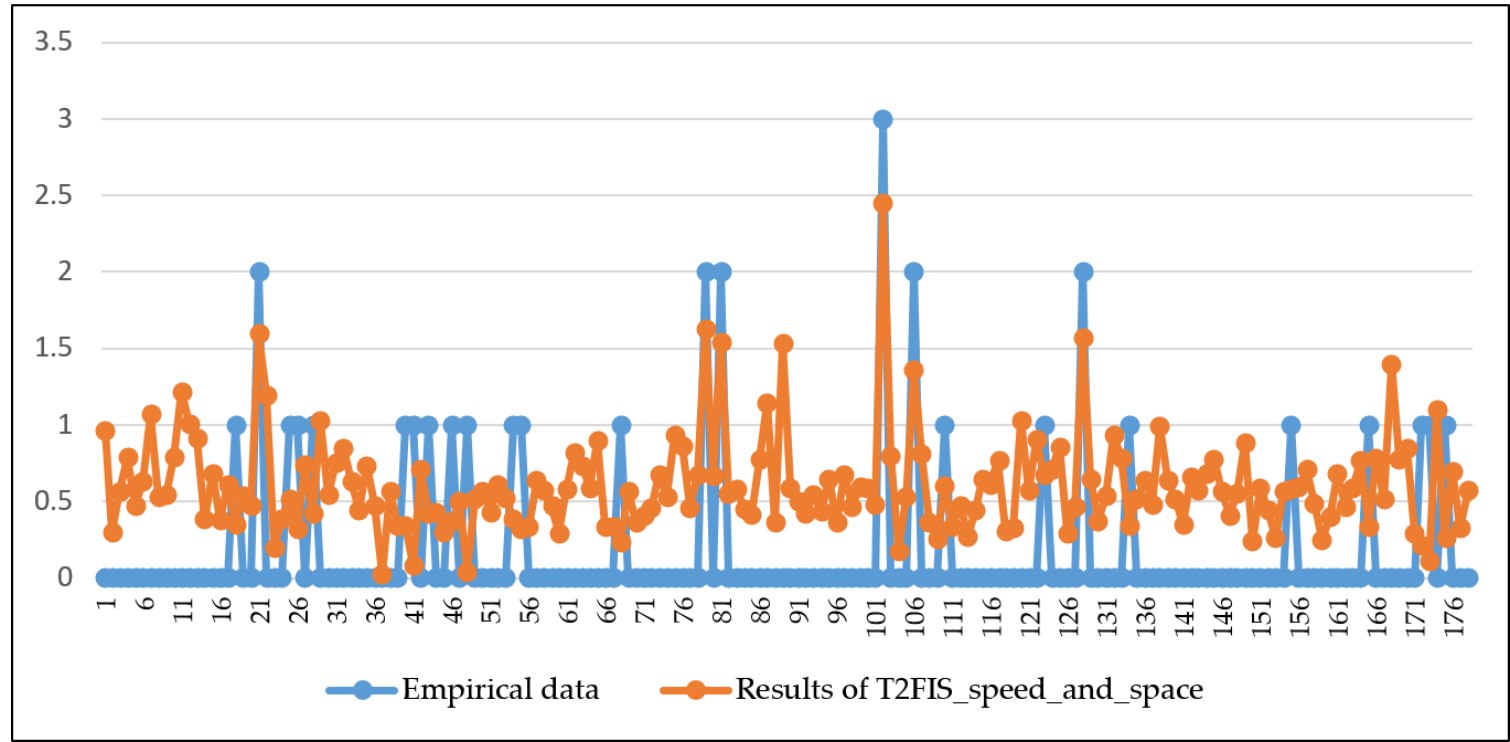

Figure 13. A comparison of empirical data and results of T2FIS in the case of speed and space capabilities assessment-T2FIS_speed_and_space.

It is interesting to note that the T2FIS with five input variables achieved the worst result. As already stated in the introduction of this paper, this can be explained by the fact that introducing more variables in the model does not necessarily lead to better results [8-10]. However, to confirm the conclusions obtained, we performed the paired $t$-test to examine whether the difference in results between T2FIS structures is statistically significant (Table 5). As is shown, there are significant differences between the results of T2FIS_space and the other two T2FIS structures. However, there is no significant difference between T2FIS_speed and T2FIS_speed_and_space. These results indicate that the space assessment capabilities can better explain the propensity for road traffic accidents of drivers compared to speed assessment capabilities. 
Table 5. The difference between cumulative deviation (CD) values per T2FIS tested by paired $t$-test.

\begin{tabular}{cccc}
\hline & T2FIS_Speed & T2FIS_Space & T2FIS_Speed_and_Space \\
\hline T2FIS_speed & - & & \\
T2FIS_space & $0.048^{*}$ & - & - \\
T2FIS_speed_and_space & 0.059 & $0.049 *$ & - \\
\hline & $* p<0.05$.
\end{tabular}

Finally, it is useful to compare the proposed approach with some other method. In this context, we compare the performance of T2FIS with the statistical technique multiple regression analysis. The results are shown in Figure 14. We further implemented a $t$-test to conclude about the statistical significance of the difference between the two approaches; however, the results show that there is no statistically significant difference in all three cases considered. It can be concluded that these two approaches give similar results.

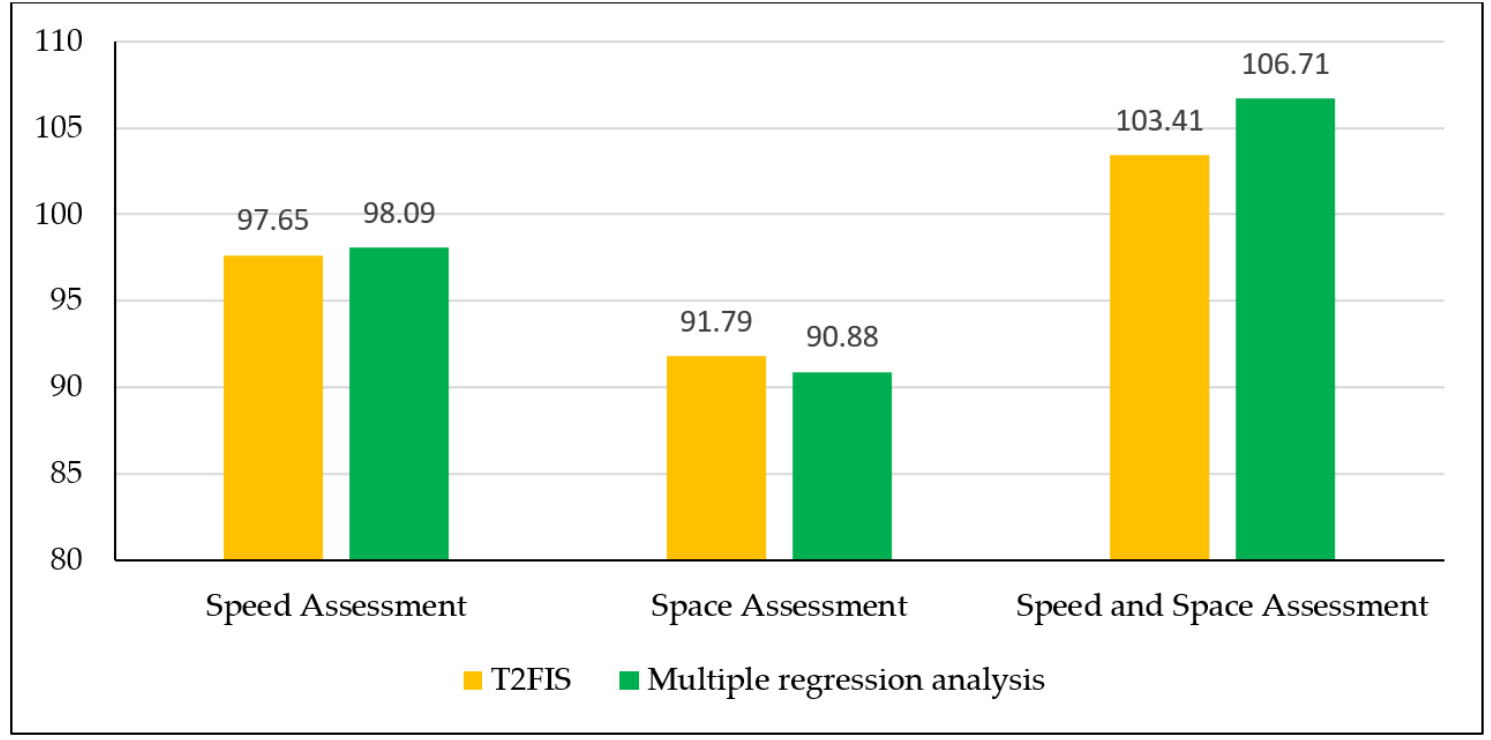

Figure 14. A comparison of T2FIS performance and multiple regression analysis.

Speaking about the performance of T2FIS, further adjustments of membership functions shape, positions, and the design of fuzzy rules can be done using some of the heuristic and metaheuristic algorithms. This would lead to even better results, and accordingly, can be considered as the recommended direction for future research.

Above all, it would be meaningful to implement certain additional methodologies based on fuzzy logic as well. One of the most popular in the literature is the fuzzy regression analysis $[53,54]$. Here, the main task is to estimate the parameters of the regression model, and these parameters represent fuzzy numbers. To solve this problem, there are three general approaches used [55]: linear and non-linear programming methods (possibilistic regression analysis), fuzzy least squares methods, and machine-learning techniques. Within these approaches, numerous sub directions exist. Having in mind that we apply Type-2 fuzzy sets in this paper, it would be interesting to compare the obtained results with Type-2 fuzzy regression analysis [56-63].

When it comes to the practical implications of this research, in the authors' opinion both speed and space capabilities are important for safe maneuvers in traffic, and this is the reason why both of them are considered in this research. However, the results obtained can be explained in the way that the drivers who record low scores on the spatial abilities test do not possess good skills related to vehicle position in the environment, which in turn could increase the likelihood of RTAs involvement. 
The result of this research can be very useful for policy-makers in the field of traffic safety. Modifications have to be undertaken to adapt education and training programs in order to improve space perception which could result in reducing the number of RTAs. The results from numerous studies confirm that spatial cognition can be improved by training [64-67]. This fact can be used when creating the training programs for young drivers applying for a driver's license, for drivers whose driver's license has been revoked, in the recruitment procedures for professional drivers, as well as, in the programs for older drivers whose spatial abilities may decline with aging. All these programs should contribute to lowering the number of RTAs in the whole world and to a higher level of safety on the roads.

\section{Conclusions}

In this paper, the authors performed the testing of the interval Type-2 fuzzy inference systems to compare the impact of speed and space perception on the occurrence of road traffic accidents. By analyzing three proposed T2FIS structures, the results of the research indicate that the space assessment characteristics better explain the participation in RTAs compared to speed assessment capabilities.

This result may be useful for improving traffic safety. Other authors also support the conclusion from this paper. Conclusions drawn from the results of our study are consistent with research showing that drivers' negligence, speeding, and misperception of space are the main causes of RTAs, while drivers being responsible for about $90 \%$ RTAs [68]. Having in mind both human and material losses that all countries globally experience due to RTAs, the need arises for this type of investigation which will contribute to the understanding of the circumstances of RTA occurrence and the development of better traffic safety measures.

The implemented methodology can be further improved in future research. Here, the statistical approach implying the multiple regression analysis and the concept of a Mamdani-based fuzzy inference system are used. It turned out that these two gave similar results. However, other approaches are welcome, such as fuzzy regression analysis, intuitionistic fuzzy sets, Sugeno fuzzy inference systems, etc. Furthermore, the optimization procedure of the current T2FIS structures would be meaningful as well. This would include the implementation of certain metaheuristic algorithms to find as good as possible shapes and positions of membership functions, as well as an adequate fuzzy rules base.

Author Contributions: Conceptualization, M.Č.-D. and L.Š.; methodology, M.Č.-D., L.̌̌. and S.Č.; software, M.D.; validation, M.Č.-D., L.Š. and A.T.; formal analysis, M.Č.-D. and A.T.; investigation, M.Č.-D.; resources, M.Č.-D., A.T. and S.Č.; data curation, M.Č.-D., A.T. and M.D.; writing—original draft preparation, M.Č.-D.; writing-review and editing, M.Č.-D.; visualization, A.T. and M.D.; supervision, L.Š.; project administration, M.Č.-D. and L.Š.; funding acquisition, M.Č.-D. and L.Š. All authors have read and agreed to the published version of the manuscript.

Funding: The article is supported by the University of Pardubice, SGS_2020_010.

Conflicts of Interest: The authors declare no conflict of interest.

\section{Appendix A}

Table A1. The fuzzy rules obtained from the empirical data in the case of joint speed and space capabilities assessment.

\begin{tabular}{ccccccc}
\hline $\boldsymbol{D}($ Rule $)$ & $\begin{array}{c}\text { Serial No. } \\
\text { of MF for } \\
\text { Variable } \boldsymbol{x}_{\mathbf{1}}\end{array}$ & $\begin{array}{c}\text { Serial No. } \\
\text { of MF for } \\
\text { Variable } \boldsymbol{x}_{\mathbf{2}}\end{array}$ & $\begin{array}{c}\text { Serial No. } \\
\text { of MF for } \\
\text { Variable } \boldsymbol{x}_{\mathbf{3}}\end{array}$ & $\begin{array}{c}\text { Serial No. } \\
\text { of MF for } \\
\text { Variable } \boldsymbol{x}_{\mathbf{4}}\end{array}$ & $\begin{array}{c}\text { Serial No. } \\
\text { of MF for } \\
\text { Variable } \boldsymbol{x}_{\mathbf{5}}\end{array}$ & $\begin{array}{c}\text { Serial No. } \\
\text { of MF for } \\
\text { Variable } \boldsymbol{y}\end{array}$ \\
\hline 0.80239 & 1 & 1 & 1 & 1 & 4 & 1 \\
0.30215 & 2 & 1 & 1 & 2 & 3 & 1 \\
0.20504 & 2 & 1 & 1 & 3 & 2 & 1 \\
0.23063 & 2 & 1 & 2 & 2 & 1 & 1 \\
\hline
\end{tabular}


Table A1. Cont.

\begin{tabular}{|c|c|c|c|c|c|c|}
\hline$D($ Rule $)$ & $\begin{array}{l}\text { Serial No. } \\
\text { of MF for } \\
\text { Variable } x_{1}\end{array}$ & $\begin{array}{l}\text { Serial No. } \\
\text { of MF for } \\
\text { Variable } x_{2}\end{array}$ & $\begin{array}{c}\text { Serial No. } \\
\text { of MF for } \\
\text { Variable } x_{3}\end{array}$ & $\begin{array}{c}\text { Serial No. } \\
\text { of MF for } \\
\text { Variable } x_{4}\end{array}$ & $\begin{array}{c}\text { Serial No. } \\
\text { of MF for } \\
\text { Variable } x_{5}\end{array}$ & $\begin{array}{l}\text { Serial No. } \\
\text { of MF for } \\
\text { Variable } y\end{array}$ \\
\hline 0.12946 & 2 & 1 & 2 & 2 & 4 & 2 \\
\hline 0.29663 & 2 & 2 & 1 & 2 & 3 & 1 \\
\hline 0.34355 & 2 & 2 & 1 & 3 & 3 & 1 \\
\hline 0.32337 & 2 & 2 & 1 & 4 & 2 & 1 \\
\hline 0.16547 & 2 & 2 & 1 & 4 & 3 & 1 \\
\hline 0.30893 & 2 & 2 & 2 & 1 & 2 & 1 \\
\hline 0.29847 & 2 & 2 & 2 & 1 & 3 & 1 \\
\hline 0.25239 & 2 & 2 & 2 & 2 & 2 & 1 \\
\hline 0.27987 & 2 & 2 & 2 & 2 & 4 & 1 \\
\hline 0.55092 & 2 & 2 & 2 & 3 & 1 & 1 \\
\hline 0.30552 & 2 & 2 & 2 & 3 & 3 & 1 \\
\hline 0.33059 & 2 & 2 & 2 & 3 & 4 & 1 \\
\hline 0.32500 & 2 & 2 & 2 & 4 & 1 & 1 \\
\hline 0.20980 & 2 & 2 & 2 & 4 & 3 & 1 \\
\hline 0.11413 & 3 & 2 & 1 & 2 & 3 & 1 \\
\hline 0.15930 & 3 & 2 & 1 & 2 & 4 & 1 \\
\hline 0.11327 & 3 & 2 & 1 & 3 & 4 & 1 \\
\hline 0.22223 & 3 & 2 & 2 & 1 & 2 & 1 \\
\hline 0.33499 & 3 & 2 & 2 & 1 & 3 & 1 \\
\hline 0.32831 & 3 & 2 & 2 & 1 & 4 & 1 \\
\hline 0.48439 & 3 & 2 & 2 & 2 & 2 & 1 \\
\hline 0.28653 & 3 & 2 & 2 & 2 & 3 & 1 \\
\hline 0.27443 & 3 & 2 & 2 & 2 & 4 & 1 \\
\hline 0.39459 & 3 & 2 & 2 & 3 & 2 & 1 \\
\hline 0.33644 & 3 & 2 & 2 & 3 & 3 & 1 \\
\hline 0.31541 & 3 & 2 & 2 & 3 & 4 & 1 \\
\hline 0.38599 & 3 & 2 & 2 & 4 & 1 & 1 \\
\hline 0.35078 & 3 & 2 & 2 & 4 & 2 & 1 \\
\hline 0.36788 & 3 & 2 & 2 & 4 & 3 & 1 \\
\hline 0.31414 & 3 & 2 & 3 & 2 & 2 & 2 \\
\hline 0.20192 & 3 & 2 & 3 & 2 & 4 & 1 \\
\hline 0.24565 & 3 & 2 & 3 & 3 & 3 & 1 \\
\hline 0.31204 & 3 & 2 & 3 & 3 & 4 & 1 \\
\hline 0.28458 & 3 & 2 & 3 & 4 & 4 & 1 \\
\hline 0.35178 & 3 & 3 & 1 & 1 & 1 & 1 \\
\hline 0.40288 & 3 & 3 & 2 & 1 & 1 & 1 \\
\hline 0.40232 & 3 & 3 & 2 & 1 & 2 & 1 \\
\hline 0.54969 & 3 & 3 & 2 & 1 & 3 & 1 \\
\hline 0.12764 & 3 & 3 & 2 & 1 & 4 & 1 \\
\hline 0.55967 & 3 & 3 & 2 & 2 & 1 & 1 \\
\hline 0.38411 & 3 & 3 & 2 & 2 & 2 & 1 \\
\hline 0.49525 & 3 & 3 & 2 & 2 & 3 & 1 \\
\hline 0.44577 & 3 & 3 & 2 & 2 & 4 & 1 \\
\hline 0.59369 & 3 & 3 & 2 & 3 & 2 & 1 \\
\hline 0.28958 & 3 & 3 & 2 & 3 & 3 & 1 \\
\hline 0.51937 & 3 & 3 & 2 & 4 & 1 & 1 \\
\hline 0.50663 & 3 & 3 & 2 & 4 & 2 & 1 \\
\hline 0.40022 & 3 & 3 & 2 & 4 & 3 & 1 \\
\hline 0.40399 & 3 & 3 & 3 & 1 & 3 & 1 \\
\hline 0.28975 & 3 & 3 & 3 & 1 & 4 & 2 \\
\hline 0.40760 & 3 & 3 & 3 & 2 & 1 & 1 \\
\hline 0.17203 & 3 & 3 & 3 & 2 & 2 & 1 \\
\hline 0.34380 & 3 & 3 & 3 & 2 & 3 & 1 \\
\hline
\end{tabular}


Table A1. Cont.

\begin{tabular}{|c|c|c|c|c|c|c|}
\hline$D($ Rule $)$ & $\begin{array}{c}\text { Serial No. } \\
\text { of MF for } \\
\text { Variable } x_{1}\end{array}$ & $\begin{array}{c}\text { Serial No. } \\
\text { of MF for } \\
\text { Variable } x_{2}\end{array}$ & $\begin{array}{c}\text { Serial No. } \\
\text { of MF for } \\
\text { Variable } x_{3}\end{array}$ & $\begin{array}{c}\text { Serial No. } \\
\text { of MF for } \\
\text { Variable } x_{4}\end{array}$ & $\begin{array}{l}\text { Serial No. } \\
\text { of MF for } \\
\text { Variable } x_{5}\end{array}$ & $\begin{array}{l}\text { Serial No. } \\
\text { of MF for } \\
\text { Variable } y\end{array}$ \\
\hline 0.28869 & 3 & 3 & 3 & 2 & 4 & 1 \\
\hline 0.51539 & 3 & 3 & 3 & 3 & 2 & 1 \\
\hline 0.39328 & 3 & 3 & 3 & 3 & 3 & 1 \\
\hline 0.33181 & 3 & 3 & 3 & 3 & 4 & 1 \\
\hline 0.16842 & 3 & 3 & 3 & 4 & 2 & 1 \\
\hline 0.23263 & 3 & 4 & 2 & 3 & 3 & 1 \\
\hline 0.15876 & 3 & 4 & 3 & 3 & 2 & 1 \\
\hline 0.16198 & 3 & 4 & 3 & 4 & 2 & 1 \\
\hline 0.12092 & 4 & 3 & 2 & 4 & 3 & 1 \\
\hline 0.21504 & 4 & 3 & 3 & 2 & 2 & 1 \\
\hline 0.19945 & 4 & 3 & 3 & 2 & 4 & 1 \\
\hline 0.14372 & 4 & 3 & 3 & 4 & 2 & 1 \\
\hline 0.13577 & 4 & 3 & 3 & 4 & 3 & 2 \\
\hline 0.29205 & 4 & 4 & 2 & 4 & 2 & 1 \\
\hline 0.26880 & 4 & 4 & 3 & 1 & 2 & 1 \\
\hline 0.37232 & 4 & 4 & 3 & 2 & 2 & 1 \\
\hline 0.38626 & 4 & 4 & 3 & 2 & 3 & 1 \\
\hline 0.29795 & 4 & 4 & 3 & 3 & 4 & 1 \\
\hline 0.30276 & 4 & 4 & 3 & 4 & 1 & 1 \\
\hline 0.40495 & 4 & 4 & 3 & 4 & 2 & 1 \\
\hline 0.28480 & 4 & 4 & 3 & 4 & 4 & 1 \\
\hline 0.19056 & 4 & 4 & 3 & 5 & 5 & 1 \\
\hline 0.30128 & 4 & 4 & 4 & 4 & 3 & 1 \\
\hline 0.33724 & 4 & 5 & 3 & 2 & 1 & 1 \\
\hline 0.51798 & 5 & 4 & 5 & 1 & 3 & 1 \\
\hline 0.07449 & 5 & 5 & 3 & 2 & 2 & 2 \\
\hline 0.50251 & 5 & 5 & 4 & 3 & 2 & 1 \\
\hline
\end{tabular}

\section{References}

1. World Health Organization. Global Tuberculosis Report 2013; World Health Organization: Geneva, Switzerland, 2013.

2. Ihueze, C.C.; Onwurah, U.O. Road traffic accidents prediction modelling: An analysis of Anambra State, Nigeria. Accid. Anal. Prev. 2018, 112, 21-29. [CrossRef] [PubMed]

3. Chen, T.Y.; Jou, R.C. Using HLM to investigate the relationship between traffic accident risk of private vehicles and public transportation. Transp. Res. Part A Policy Pract. 2019, 119, 148-161. [CrossRef]

4. Jacobs, G.; Aeron-Thomas, A.; Astrop, A. Estimating Global Road Fatalities; Department for International Development: London, UK, 2000.

5. World Health Organization. Global Status Report on Road Safety 2015; World Health Organization: Geneva, Switzerland, 2015.

6. Saccomanno, F.F.; Grossi, R.; Greco, D.; Mehmood, A. Identifying black spots along highway SS107 in Southern Italy using two models. J. Transp. Eng. 2001, 127, 515-522. [CrossRef]

7. Fan, Z.; Liu, C.; Cai, D.; Yue, S. Research on black spot identification of safety in urban traffic accidents based on machine learning method. Saf. Sci. 2019, 118, 607-616. [CrossRef]

8. Lin, L.; Wang, Q.; Sadek, A.W. A novel variable selection method based on frequent pattern tree for real-time traffic accident risk prediction. Transp. Res. Part C Emerg. Technol. 2015, 55, 444-459. [CrossRef]

9. Sawalha, Z.; Sayed, T. Traffic accident modeling: Some statistical issues. Can. J. Civ. Eng. 2006, 33, 1115-1124. [CrossRef]

10. Fernández, A.; Gómez, Á.; Lecumberry, F.; Pardo, Á.; Ramírez, I. Pattern recognition in Latin America in the “Big Data” era. Pattern Recogn. 2015, 48, 1185-1196. [CrossRef]

11. Ryder, B.; Dahlinger, A.; Gahr, B.; Zundritsch, P.; Wortmann, F.; Fleisch, E. Spatial prediction of traffic accidents with critical driving events-Insights from a nationwide field study. Transp. Res. Part A Policy Pract. 2019, 124, 611-626. [CrossRef] 
12. Ryder, B.; Gahr, B.; Egolf, P.; Dahlinger, A.; Wortmann, F. Preventing traffic accidents with in-vehicle decision support systems-The impact of accident hotspot warnings on driver behavior. Decis. Support Syst. 2017, 99, 64-74. [CrossRef]

13. Trifunović, A.; Pešić, D.; Čičević, S.; Antić, B. The importance of spatial orientation and knowledge of traffic signs for children's traffic safety. Accid. Anal. Prev. 2017, 102, 81-92. [CrossRef] [PubMed]

14. Cornoldi, C.; Vecchi, T. Visuo-Spatial Working Memory and Individual Differences; Psychology Press: London, UK, 2004. [CrossRef]

15. Trifunović, A.; Čičević, S.; Lazarević, D.; Dragović, M.; Vidović, N.; Mošić, M.; Otat, O. Perception of 3D virtual road markings: Based on estimation of vehicle speed. FME Trans. 2019, 47, 360-369. [CrossRef]

16. Aarts, L.; Van Schagen, I. Driving speed and the risk of road crashes: A review. Accid. Anal. Prev. 2006, 38, 215-224. [CrossRef] [PubMed]

17. Dakic, I.; Stevanovic, A. On development of arterial fundamental diagrams based on surrogate density measures from adaptive traffic control systems utilizing stop-line detection. Transp. Res. Part C Emerg. Technol. 2018, 94, 133-150. [CrossRef]

18. Rudin-Brown, C.M. Vehicle height affects drivers' speed perception: Implications for rollover risk. Transp. Res. Record. 2004, 1899, 84-89. [CrossRef]

19. Kloeden, C.N.; McLean, A.J.; Moore, V.M.; Ponte, G. Travelling Speed and the Risk of Crash Involvement Volume 2-Case and Reconstruction Details; NHMRC Road Accident Research Unit, The University of Adelaide: Adelaide, Australia, 1997.

20. Kloeden, C.N.; McLean, J.; Glonek, G.F.V. Reanalysis of Travelling Speed and the Risk of Crash Involvement in Adelaide South Australia; Australian Transport Safety Bureau: Adelaide, Australia, 2002.

21. Kloeden, C.N.; Ponte, G.; McLean, J. Travelling Speed and Risk of Crash Involvement on Rural Roads; Australian Transport Safety Bureau: Adelaide, Australia, 2001.

22. Wang, C.; Quddus, M.; Ison, S. The effects of area-wide road speed and curvature on traffic casualties in England. J. Transp. Geogr. 2009, 17, 385-395. [CrossRef]

23. Baruya, A. Speed-accident relationships on European roads. In Proceedings of the 9th International Conference "Road Safety in Europe”, Bergisch Gladbach, Germany, 21-23 September 1998.

24. Gitelman, V.; Doveh, E.; Bekhor, S. The relationship between free-flow travel speeds, infrastructure characteristics and accidents, on single-carriageway roads. Transp. Res. Proc. 2017, 25, 2026-2043. [CrossRef]

25. Elvik, R.; Christensen, P.; Amundsen, A.H. Speed and Road Accidents an Evaluation of the Power Model; Institute of Transport Economics (TØI): Oslo, Norway, 2004.

26. Quddus, M. Exploring the relationship between average speed, speed variation, and accident rates using spatial statistical models and GIS. J. Transp. Saf. Secur. 2013, 5, 27-45. [CrossRef]

27. Road Traffic Safety Agency. Statistical Report on the State of Traffic Safety in the Republic of Serbia in 2019; Road Traffic Safety Agency: Belgrade, Serbia, 2020.

28. Road Traffic Safety Agency. On Line Statistical Report on the State of Traffic Safety in the Republic of Serbia for the Years from 2017 to 2019; Road Traffic Safety Agency: Belgrade, Serbia, 2020. Available online: http://195.222.99.60/ibbsPublic/ (accessed on 25 July 2020).

29. Endsley, M.R. Toward a theory of situation awareness in dynamic systems. Hum. Factors 1995, 37, 32-64. [CrossRef]

30. Day, M.R.; Thompson, A.R.; Poulter, D.R.; Stride, C.B.; Rowe, R. Why do drivers become safer over the first three months of driving? A longitudinal qualitative study. Accid. Anal. Prev. 2018, 117, 225-231. [CrossRef]

31. Haddon, W., Jr. Advances in the epidemiology of injuries as a basis for public policy. Public Health Rep. 1980, 95, 411-421.

32. Holmes, B.D.; Haglund, K.; Ameh, E.A.; Olaomi, O.O.; Uthman, U.; Cassidy, L.D. Understanding Etiologies of Road Traffic Crashes, Injuries, and Death for Patients at National Hospital Abuja: A Qualitative Content Analysis Using Haddon's Matrix. Qual. Rep. 2020, 25, 962-974.

33. Čubranić-Dobrodolac, M.; Švadlenka, L.; Čičević, S.; Dobrodolac, M. Modelling driver propensity for traffic accidents: A comparison of multiple regression analysis and fuzzy approach. Int. J. Inj. Control Saf. Promot. 2020, 27, 156-167. [CrossRef] [PubMed]

34. Lee, D.; Donnell, E.T. Analysis of nighttime driver behavior and pavement marking effects using fuzzy inference system. J. Comput. Civ. Eng. 2007, 21, 200-210. [CrossRef] 
35. Sentouh, C.; Nguyen, A.-T.; Rath, J.J.; Floris, J.; Popieul, J.-C. Human-machine shared control for vehicle lane keeping systems: A Lyapunov-based approach. IET Intell. Transp. Syst. 2019, 13, 63-71. [CrossRef]

36. Riaz, F.; Khadim, S.; Rauf, R.; Ahmad, M.; Jabbar, S.; Chaudhry, J. A validated fuzzy logic inspired driver distraction evaluation system for road safety using artificial human driver emotion. Comput. Netw. 2018, 143, 62-73. [CrossRef]

37. Lin, C.-T.; Tsai, S.-F.; Ko, L.-W. EEG-based learning system for online motion sickness level estimation in a dynamic vehicle environment. IEEE Trans. Neural Netw. Learn. Syst. 2013, 24, 1689-1700. [CrossRef]

38. Dorr, D.; Grabengiesser, D.; Gauterin, F. Online driving style recognition using fuzzy logic. In Proceedings of the IEEE 17th International Conference on Intelligent Transportation Systems (ITSC), Qingdao, China, 8-11 October 2014; pp. 1021-1026. [CrossRef]

39. Saleh, M.; Aljaafreh, A.; Albdour, N. Fuzzy-based recognition model for driving styles. (IJEECS) Int. J. Electr. Electron. Comput. Syst. 2013, 16, 816-819.

40. Bıçaksız, P.; Öztürk, I.; Özkan, T. The differential associations of functional and dysfunctional impulsivity with driving style: A simulator study. Transp. Res. Part F Traffic Psychol. Behav. 2019, 63, 1-11. [CrossRef]

41. Pešić, D.; Trifunović, A.; Ivković, I.; Čičević, S.; Žunjić, A. Evaluation of the effects of daytime running lights for passenger cars. Transp. Res. Part F Traffic Psychol. Behav. 2019, 66, 252-261. [CrossRef]

42. Allen, M.J.; Clark, J.R. Automobile running lights-A research report. Optom. Vis. Sci. 1964, 47, 329-345. [CrossRef]

43. Dahlstedt, S.; Rumar, K. Vehicle Colour and Front Conspicuity in Some Simulated Rural Traffic Situations; Traffic Safety Research Group, Department of Psychology, University of Uppsala: Uppsala, Sweden, 1973.

44. Government of the Republic of Serbia. Law on Road Traffic Safety; Official Gazette: Belgrade, Serbia, 2019.

45. Čičević, S.; Trifunović, A.; Mitrović, S.; Nešic, M. The usability analysis of a different presentation media design for vehicle speed assessment. In Ergonomic Design and Assessment of Products and Systems; Žunjić, A., Ed.; Nova Science: New York, NY, USA, 2017; pp. 195-220.

46. Tse, P.U. Abutting Objects Warp the Three-Dimensional Curvature of Modally Completing Surfaces. i-Perception 2020, 11, 1-15. [CrossRef] [PubMed]

47. Toscani, M.; Valsecchi, M. Lightness discrimination depends more on bright rather than shaded regions of three-dimensional objects. i-Perception 2019, 10, 1-10. [CrossRef] [PubMed]

48. Mamdani, E.H.; Assilian, S. An experiment in linguistic synthesis with a fuzzy logic controller. Int. J. Man-Mach. Stud. 1975, 7, 1-13. [CrossRef]

49. Zadeh, L.A. The Concept of a Linguistic Variable and Its Application to Approximate Reasoning-1. Inform. Sci. 1975, 8, 199-249. [CrossRef]

50. Wang, L.-X.; Mendel, J.M. Generating fuzzy rules by learning from examples. IEEE Trans. Syst. Man Cybern. 1992, 22, 1414-1427. [CrossRef]

51. Jovčić, S.; Průša, P.; Dobrodolac, M.; Švadlenka, L. A proposal for a decision-making tool in third-party logistics (3PL) provider selection based on multi-criteria analysis and the fuzzy approach. Sustainability 2019, 11, 4236. [CrossRef]

52. Čubranić-Dobrodolac, M.; Molkova, T.; Švadlenka, L. The impact of road characteristics assessment on the traffic accidents occurrence. In Proceedings of the Sinteza 2019-International Scientific Conference on Information Technology and Data Related Research, Belgrade, Serbia, 20 April 2019; Singidunum University: Belgrade, Serbia, 2019; pp. 26-31. [CrossRef]

53. Tanaka, H.; Uejima, S.; Asai, K. Linear regression analysis with fuzzy model. IEEE Trans. Syst. Man Cybern. 1982, 12, 903-907. [CrossRef]

54. Tanaka, H. Fuzzy data analysis by possibilistic linear models. Fuzzy Sets Syst. 1987, 24, 363-375. [CrossRef]

55. Chukhrova, N.; Johannssen, A. Fuzzy regression analysis: Systematic review and bibliography. Appl. Soft Comput. 2019, 84, 105708. [CrossRef]

56. Wei, Y.; Watada, J. Building a Type II Fuzzy Qualitative Regression Model. In Intelligent Decision Technologies; Smart Innovation, Systems and Technologies; Watada, J., Watanabe, T., Phillips-Wren, G., Howlett, R., Jain, L., Eds.; Springer: Berlin/Heidelberg, Germany, 2012; Volume 15. [CrossRef]

57. Poleshchuk, O.; Komarov, E. A Fuzzy Nonlinear Regression Model for Interval Type-2 Fuzzy Sets. Int. J. Math. Comput. Sci. 2014, 8, 840-844. [CrossRef]

58. Hosseinzadeh, E.; Hassanpour, H.; Arefi, M. A weighted goal programming approach to fuzzy linear regression with crisp inputs and type-2 fuzzy outputs. Soft Comput. 2015, 19, 1143-1151. [CrossRef] 
59. Darwish, A.; Poleshchuk, O.; Komarov, E. A New Fuzzy Linear Regression Model for a Special Case of Interval Type-2 Fuzzy Sets. Appl. Math. Inform. Sci. 2016, 10, 1209-1214. [CrossRef]

60. Wei, Y.; Watada, J. Building a type-2 fuzzy regression model based on credibility theory and its application on Arbitrage Pricing theory. IEEJ Trans. Electr. Electron. Eng. 2016, 11, 720-729. [CrossRef]

61. Bajestani, N.S.; Kamyad, A.V.; Zare, A. A piecewise type-2 fuzzy regression model. Int. J. Comput. Intell. Syst. 2017, 10, 734-744. [CrossRef]

62. Bajestani, N.S.; Kamyad, A.V.; Esfahani, E.N.; Zare, A. Prediction of retinopathy in diabetic patients using type-2 fuzzy regression model. Eur. J. Oper. Res. 2018, 264, 859-869. [CrossRef]

63. Gao, P.; Gao, Y. Quadrilateral Interval Type-2 Fuzzy Regression Analysis for Data Outlier Detection. Math. Probl. Eng. 2019, 2019, 4914593. [CrossRef]

64. Spence, I.; Yu, J.J.; Feng, J.; Marshman, J. Women match men when learning a spatial skill. J. Exp. Psychol. Learn 2009, 35, 1097-1103. [CrossRef]

65. Spence, I.; Feng, J. Video Games and Spatial Cognitio. Rev. Gen. Psychol. 2010, 14, 92-104. [CrossRef]

66. Feng, J.; Spence, I.; Pratt, J. Playing an action video game reduces gender differences in spatial cognition. Psychol. Sci. 2007, 18, 850-855. [CrossRef]

67. Milani, L.; Grumi, S.; Di Blasio, P. Positive Effects of Videogame Use on Visuospatial Competencies: The Impact of Visualization Style in Preadolescents and Adolescents. Front. Psychol. 2019, 10, 1226. [CrossRef]

68. Ali, G.A.; Tayfour, A. Characteristics and prediction of traffic accident casualties in Sudan using statistical modeling and artificial neural networks. Int. J. Transp. Sci. Technol. 2012, 1, 305-317. [CrossRef]

(C) 2020 by the authors. Licensee MDPI, Basel, Switzerland. This article is an open access article distributed under the terms and conditions of the Creative Commons Attribution (CC BY) license (http://creativecommons.org/licenses/by/4.0/). 